\title{
Original article (full paper) \\ Stretch breaks in the work setting improve flexibility and grip strength and reduce musculoskeletal complaints
}

\author{
Patrícia Fátima de Oliveira Martins \\ Evelin Alvares Aranda Zicolau \\ Maria Fernanda Cury-Boaventura \\ Universidade Cruzeiro do Sul, São Paulo, Brazil
}

\begin{abstract}
This study investigated the effect of a stretch break program (SBP) on the flexibility, strength and musculoskeletal complaints of storage (SW) and administrative (AW) sector workers. Twenty-six male workers were randomly selected: 16 workers from the storage sector and ten workers from the administrative sector. We applied the Physical Activity Questionnaire and Musculoskeletal Questionnaire and evaluated flexibility and grip strength before and after 6 months of the SBP. The SPB decreased the SW group members' complaints of paresthesias and numbness in the upper body and total body. The SPB reduced the AW group members' complaints of paresthesias and numbness in the upper body. Furthermore, the SPB improved cervical, trunk and left shoulder flexibility in the SW group and improved cervical and shoulder flexibility and grip strength in the AW group. The SBP contribute to improve flexibility and musculoskeletal complaints in the regions that are affected by higher rates of work-related injuries.
\end{abstract}

Keywords: flexibility, musculoskeletal symptoms, strength, stretch break, workers

Resumo - "Programa de ginástica laboral melhora a flexibilidade e força de preensão e reduz queixas osteomusculares em trabalhadores." O presente estudo investigou o efeito de um programa de ginática laboral (PGL) na flexibilidade, força e sintomas osteomusculares nos trabalhadores dos setores almoxarifado (GTA) e administrativo (GTAD). Vinte e seis trabalhadores do sexo masculino foram selecionados aleatoriamente: dezesseis GTA e dez GTAD. Aplicamos os questinários de atividade física e de sintomas osteomusculares e avaliamos a flexibilidade e força de preensão manual antes e após seis meses da PGL. O PGL diminuiu o número de queixas de parestesias e dormência dos membros superiores e no corpo total no GTA. O PGL reduziu o número de queixas de parestesias e dormência dos membros superiorese no GTAD. Além disso, o PGL melhorou a flexibilidade da cervical, do tronco e do ombro esquerdo no grupo GTA e a flexibilidade da cervical e ombro e força de preensão no grupo GTAD. O PGL contribuiu para melhoria da flexibilidade e queixas osteomusculares nas regiões corporais com maiores índices de lesões provenientes do trabalho.

Palavras-chave: flexibilidade, força, ginástica laboral, trabalhadores, sintomas musculo-esqueléticos

Resumen - "Programa de gimnasia laboral mejora la flexibilidad y la fuerza de prensión y reduce las quejas musculoesqueléticas en los trabajadores." El presente estudio investigó el efecto de un programa de gimnasia laboral (PGL) en la flexibilidad, la fuerza y síntomas musculoesqueléticos en los sectores trabajadores de almacén (GTA) y administrativa (GTAD). Veintiséis trabajadores de sexo masculino fueron seleccionados aleatoriamente: dieciséis GTA y diez GTAD. Aplicamos las questinários de la actividad física y los síntomas musculoesqueléticos y evaluamos la flexibilidad y fuerza de presión antes y después de 6 meses de PGL. El PGL disminuyó el número de quejas por parestesias y de entumecimiento de la parte superior del cuerpo y cuerpo total en el GTA. El PGL redujo el número de quejas por parestesias y entumecimiento de los miembros superiorese en GTAD. Además, PGL mejoró la flexibilidad del cervical, el tronco y el hombro izquierdo en el grupo de GTA y flexibilidade del hombro, el cervical y la fuerza de prensión en el grupo GTAD. El PGL contribuyó a mejorar la flexibilidad y musculoesqueléticos quejas en regiones del cuerpo con las mayores tasas de lesiones de trabajo.

Palabras claves: flexibilidad, la fuerza, la gimnasia laboral, los trabajadores, los síntomas musculoesqueléticos

\section{Introduction}

Cumulative trauma disorder is a collection of musculoskeletal disorders characterized by chronic discomfort, pain and possibly functional impairment (Trujillo \& Zeng, 2006). Repetitive movements are commonly performed and abnormal or prolonged postures or positions are commonly assumed during many work activities, such as administrative or storage duties, 
and these motions can cause cumulative trauma disorder (Dick, Graveling, Munro, \& Walker-Bone, 2011, Lowe \& Dick, 2015). These activities lead to muscle imbalance, which results in a mechanical disadvantage and weakness. In addition, these activities may increase the pressure around a nerve, stretch the nerve, or decrease blood flow, thereby producing fibrosis in the nerve (Trujillo \& Zeng, 2006; Varatharajan et al., 2014).

In Europe, $25 \%$ of workers report work-related neck/shoulder pain, and $15 \%$ report work-related arm pain (Kraker \& Blatter, 2005). Between 2002 and 2004 in the Netherlands, 28\% of workers reported experiencing neck/shoulder or elbow/wrist/ hand symptoms caused by work activities during the previous 12 months; moreover, 2 to $4 \%$ of all workers use their yearly sick leave for work-related neck and upper limb problems, which account for 4 to $6 \%$ of the total number of sick days and last for 3 to 4 years on average (Heinrich \& Blatter, 2005). High work demands and minimal levels of control at work are often related to these types of symptoms (Bongers, Ijmker, van den Heuvel, \& Blatter, 2006). In the Netherlands the yearly costs of work-related neck/upper limb symptoms were estimated at 2.1 billion euros, counting decreased productivity, chronic incapacity, sick leave, and medical expenses (Bernaards, Ariens, \& Hildebrandt, 2006). However, in the last decade, the incidence of work-related disabilities caused by neck and upper limb symptoms has decreased to $2 \%$ (Van den Heuvel, Van der Beek, Blatter, \& Bongers, 2006).

Workplace health promotion (WHP) programs may be important for alleviating discomfort, pain, tension, visual tiredness, fatigue and psychiatric disorders in workers. WHP programs include employee education, modified workspace designs, adjusting work habits and promoting exercise, stretches and short rest breaks. The physiologic benefits of a stretch break program include reduced intervertebral disc pressure, increased blood flow, reductions in muscle lactic acid and increased attention (Andersen et al., 2012; Balci \& Aghazadeh, 2003; Cheema et al., 2013; Varatharajan et al., 2014; Zebis et al., 2011).

Previous studies have demonstrated the effects that additional breaks have on reducing musculoskeletal discomfort (Balci \& Aghazadeh, 2004; McLean et al., 2001). However, the studies by Karwowski et al. (Karwowski, Eberts, Salvendy, \& Noland, 1994) and Henning et al. (Henning, Jacques, Kissel, Sullivan, \& Alteras-Webb, 1997) did not reveal a positive effect of added breaks. A recent systematic review concluded that few high-quality studies have examined the effect of office ergonomic interventions on health; the interventions that focused on rest breaks (four studies) yielded mixed evidence supporting the positive impact of rest breaks on musculoskeletal health and moderate evidence (two studies) that rest breaks with stretching exercises had no impact on musculoskeletal health (Brewer et al., 2006). More studies are needed to reach a more definitive conclusion about the effectiveness of added rest breaks.

In the current prospective cohort study, we investigated the effects of a stretch break program (SBP) on the flexibility, strength, and musculoskeletal symptoms of storage workers (SW) and administrative workers (AW).

\section{Methods}

\section{Subjects}

Twenty-six healthy male workers participated in this prospective cohort study. Information about the volunteers' health was obtained from the company's Occupational Health Medical Control Program (OHMCP); none of participants were taking daily medications or prescription medications. This study was conducted in strict accordance with the recommendations proposed by the Guide for the Care and Use of Humans and Ethics Committee of the University Cruzeiro do Sul by the São Paulo, Brazil approved the study (Permit Number: 026/2009).

\section{Experimental design}

We recruited forty-three male workers from two work sectors in a sports equipment distributor in São Paulo, Brazil. We excluded the participants who were fired during the study (15), a worker who did not join the program (1) and a worker who worked in more than one sector (1). We selected sixteen workers from the storage sector (SW; age: $28 \pm 2.1$ years, body mass: $77 \pm 3.6 \mathrm{~kg}$, height: $175 \pm 2.1 \mathrm{~cm}$ and BMI: $\left.24.8 \pm 0.7 \mathrm{~kg} / \mathrm{m}^{2}\right)$, and 10 from the administrative sector (AW; age: $30 \pm 2.9$ years old, body mass: $79 \pm 4.3 \mathrm{~kg}$, height: $179 \pm 1.9 \mathrm{~cm}$ and BMI: $24.7 \pm 1.0 \mathrm{~kg} / \mathrm{m}^{2}$ ). There were no changes in the demographic characteristics of the groups before and after the 6-month SBP. We also found no differences between the groups (Table 1).

Table 1. Demographic characteristics before and after the 6-month stretch break program.

\begin{tabular}{lcccc}
\hline & Before & After & Before & After \\
\cline { 2 - 5 } & \multicolumn{2}{c}{ SW } & \multicolumn{2}{c}{ AW } \\
\hline Volunteers & \multicolumn{2}{c}{16} & \multicolumn{2}{c}{10} \\
Age (years) & $28 \pm 2$ & $28 \pm 2$ & $30 \pm 3$ & $30 \pm 3$ \\
Weight (Kg) & $77 \pm 4$ & $77 \pm 3$ & $79 \pm 4$ & $79 \pm 4$ \\
Height (cm) & $175 \pm 2$ & $175 \pm 2$ & $179 \pm 2$ & $179 \pm 2$ \\
BMI (kg/m $)$ & $25 \pm 1$ & $25.0 \pm 1$ & $25 \pm 1$ & $25 \pm 1$ \\
\hline
\end{tabular}

The values are expressed as the mean + SEM. SW $=$ storage workers and AW = computer-using administrative workers.

All of the subjects participated in the SBP and performed occupational activities in one sector only. The occupational activities of both groups required distinct abilities and postures according to the information obtained from the participating company's Occupational Health Medical Control Program (OHMCP). The SW group accepts delivery items and storage of such items; prepares, alters and processes new or used sports equipment and garment and inventories for delivery to customers; maintains inventory levels and their records, receives new materials from vendors and notifies supervision of problems such as back orders or wrong items sent; prepare products according to route, customer and individual user, then place into route carts/bins for loading into delivery vehicles or designated area. The AW group work at a rate to keep up with the flow of products and delivery date 
requirements and place garment orders using a computer, phone or fax, maintain inventory levels, perform withdrawals, inventories, maintain records and prepare reports or orders. The performed the SBP at the beginning of their workday in preparation for their work activities. For six consecutive months, the workers performed the SBP for 15 minutes at a time, three times per week for the SW groups and two times per week for the AW group. The subjects also received monthly educational information notices and satisfaction surveys and were monitored via daily attendance records and monthly sector reports.

Physical education teacher developed SBP monthly, safely and progressively over the six month intervention period and were primarily selected to correspond to the musculature the workers used during their workday. The physical education professional introduced and performed the exercises, corrected the participants and coordinated the educational information notices and satisfaction surveys. All of the exercises satisfied biomechanical criteria for safety and practical criteria to ensure minimal work disruption. The exercises were progressive according to fitness acquired by the workers increasing the number of sets, repetition and/ or exercise time.
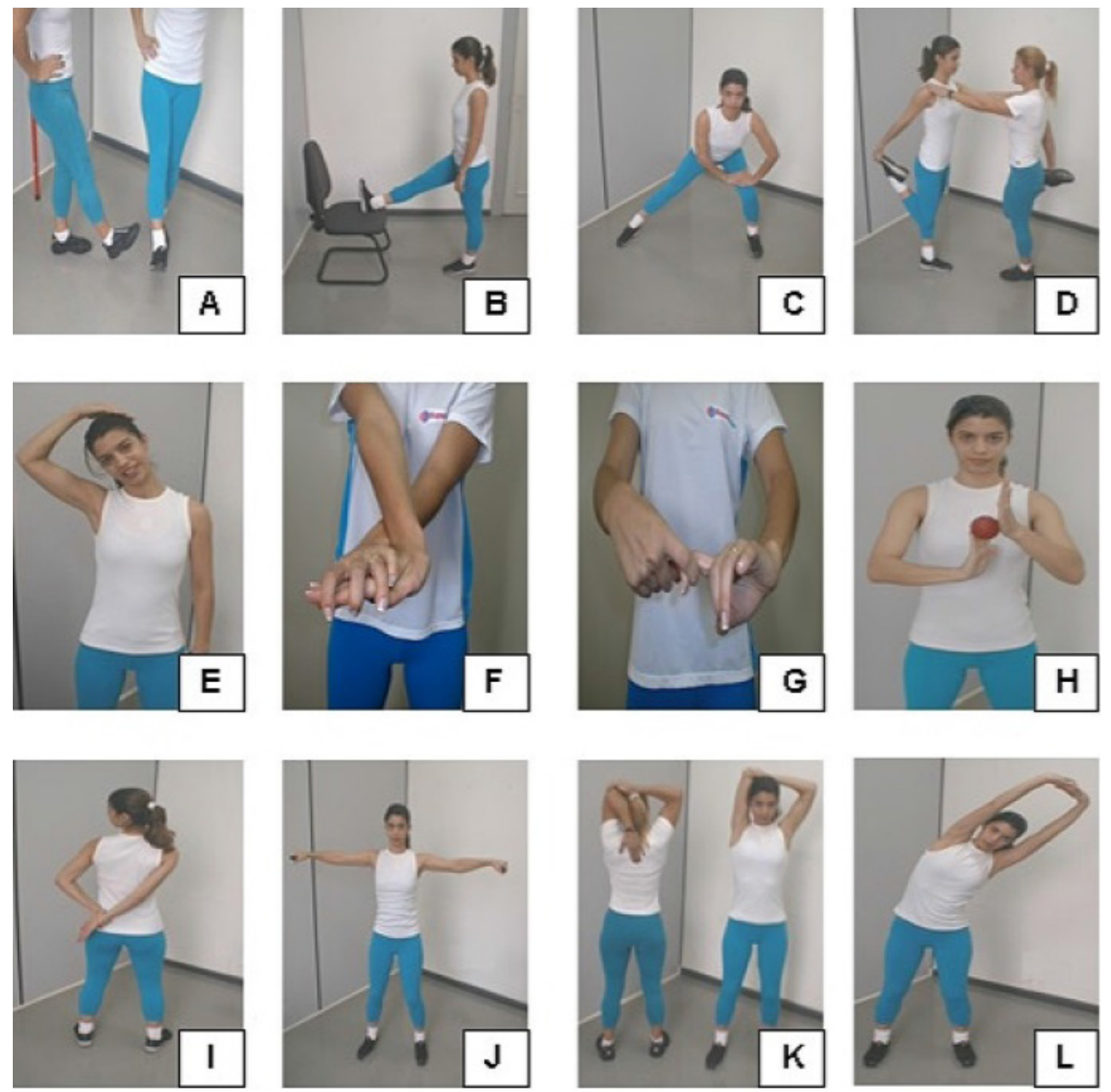
warm-up (3 minutes), static and dynamic stretching exercises (10 minutes) and relaxation (2 minutes). In the first and third week of the month, we gave special attention to muscle groups of the shoulders, neck, trunk, hand, fingers, hip, thigh and knee in the SW and AW. In the second and fourth week of the month elbow, forearm, hip, thigh, ankle and foot muscle groups was prioritized to the SW groups and elbow, forearm, hand, fingers, hip, thigh, ankle and foot muscle groups to AW (Appendix 1). In each session, we applied approximately 10 exercises including 2 to 3 resistance exercises and 7 to 8 static or dynamic stretching. Static stretching was done through exercises with maintenance of posture during 20-30 seconds; dynamic stretching was carried by 1 or 2 workout series of 8 to 10 repetitions and resistance exercise by 2-3 sets of 10 repetitions (Figure 1).

We used Yellow / Red and Thin / Medium Theraband Resistance Bands ${ }^{\mathrm{TM}}$ in resistance exercise for AW and Red / Green and Medium / Heavy Theraband Resistance Bands ${ }^{\mathrm{TM}}$ for SW. We prioritized dynamic stretching with the recruitment of a larger number of joints and muscle groups in each exercise in the SW and static stretch with the selective and progressive recruitment of joints and muscle groups in the AW (Figure 2). 

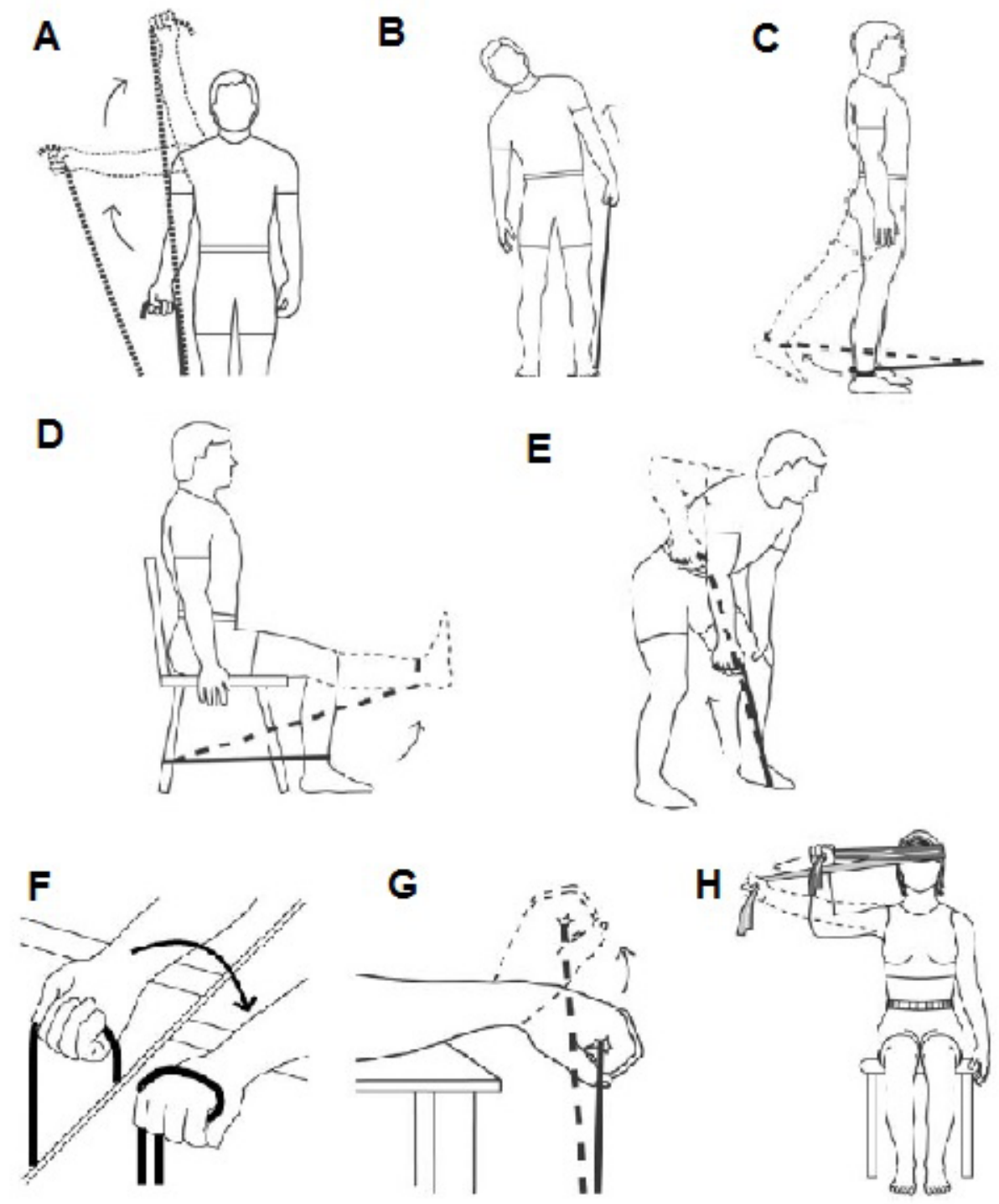

Figure 2. Representative exercises of SBP in AW and SW using resistance bands: shoulder (A), shoulder and trunk (B), hip (C), knee (D), elbow $(E)$, wrist and forearm $(F)$, fingers and wrist $(G)$ and neck $(H)$.

\section{International Physical Activity Questionnaire (IPAQ)}

We administered the International Physical Activity Questionnaire (IPAQ) short form in an interview by the researchers during the baseline health assessment. We used IPAQ to measure the participants' self-reported total physical activity, including work-related activities, transportation, domestic and leisure-time physical activities and walking as well as moderate- and vigorous-intensity physical activity over the previous 7 days (Wolin, Heil, Askew, Matthews, \& Bennett, 2008). We calculated the Physical activity in terms of metabolic equivalent (MET)-minutes per week as follows: MET level x minutes of activity/day $\mathrm{x}$ days per week. The MET levels were defined as follows: walking $=3.3$ METs, moderate intensity $=4.0$ METs and vigorous intensity $=8.0$ METs (Wolin et al., 2008).

\section{Grip strength}

We measured grip strength using a dynamometer $\left(J_{A M A R}{ }^{\circledR}\right.$, Canada), according to the method described by Peters et al. (Peters et al., 2011). The Jamar dynamometer was placed in the participant's dominant side hand (DS) and non-dominant side (NDS) hand, and the examiner loosely held the readout dial to prevent the participant from dropping it. The volunteers performed three maximum voluntary contractions by each hand in alternating order. We used mean value for each hand for the 
analysis. All of the participants were examined in a standardized position. Grip strength was expressed in kilograms $(\mathrm{kg})$.

\section{Flexibility measurements}

\section{Sit-and-reach test}

We used a sit-and-reach test to assess flexibility. We used a Wells' bench (Personal Sanny, São Bernardo do Campo, Brazil), a box that measured $31 \mathrm{~cm}$ in height and $64 \mathrm{~cm}$ in length (with a top plate $41 \mathrm{~cm}$ in width). The first $23 \mathrm{~cm}$ of the top plate was extended over the front edge of the box towards the subject's feet. The adults sit with their knees straight and reach forward as far as possible from a seated position. The furthest position they reached with their fingertips determined the score. We performed three trials and recorded the highest score (Canadian Ministry of State, 1987).

\section{Fleximeter}

Leighton fleximeter (Code Research Institute, Brazil) composed of a small circular box with two $360^{\circ}$ scales and a gravity-powered reading needle was used to measure axial and large-joint flexibility. The fleximeter was attached to Velcro and tied to the distal third of the articulation segment to be measured in parallel with the articulation, without compromising the width of the movement, while the reading needle was calibrated to zero. The subject executed the movement until he or she reached the maximum point that could be read. The axial and large joints included the cervical spine (lateral flexion), the shoulder (extension) and the trunk (lateral flexion) (Leighton, 1987). The device was reset after each of the three movements. The procedure was performed on the right and left sides, and the average registered values were used.

\section{Nordic Musculoskeletal Questionnaire (NMQ)}

A one-page questionnaire was included within the larger survey, and identical questions regarding the participants' pain and its consequences were asked independently for each of the three spinal regions. The questions relating to three regions of the spine were followed up for drawings that display the anatomical limits of the lumbar, thoracic and cervical. The participants were asked to reflect on their pain and its consequences for each spinal region separately. The questions were based on the standardized Nordic Musculoskeletal Questionnaire. The following variables were included: pain that has ever occurred, pain within the past year, the number of days with pain during the past year (categorized as " $\leq 30$ days" and " $>30$ days") and pain radiating from the region of complaint (i.e., into the leg, chest or arm). The following independent variables were used to measure the consequences of back pain during the past year: "sought care," "reduced physical activity," "took sick leave," "changed work/work duties" and "sought/received disability pension" (the latter two variables were analyzed in relation to the "pain that has ever occurred" variable) (Kuorinka et al., 1987).

\section{Statistical analysis}

The data were entered into GraphPad Prism Version 5.0 (San Diego CA, EUA) and analyzed. The results were expressed as the mean \pm standard error of mean (SEM) for 10 to 16 workers. The statistical analysis was performed using a paired t-test for comparing the quantitative data before and after 6 months of the SBP and for comparing the right and left sides (DS and NDS). To compare the number of participants with musculoskeletal symptoms before and after 6 months of the SBP we performed a paired test-t of the square root. A $p$ value of $<.05$ was considered statistically significant.

\section{Results}

\section{Physical activity levels}

Based on the MET number/week, there were no observed differences after participation in the 6-month SBP in the amount of walking (from $587 \pm 80$ to $664 \pm 124, p=.58$ ), moderate activity (from $203 \pm 95$ to $293 \pm 82, p=.41$ ), vigorous activity (from $487 \pm 210$ to $747 \pm 220, p=.29$ ) and total activity (from $1278 \pm 310$ to $1706 \pm 378, p=.28$ ) performed by the $\mathrm{SW}$, and there were no differences in the amount of walking (from 552 \pm 113 to $472 \pm 88, p=.56$ ), moderate activity (from $328 \pm 101$ to $588 \pm 213, p=.24$ ), vigorous activity (from $160 \pm 84$ to 456 $\pm 282, p=.38$ ) and total activity (from $1040 \pm 231$ to $1352 \pm$ $395, p=.26$ ) performed by the AW groups (Table 2).

Table 2. Metabolic equivalents per week before and after the 6-month stretch break program.

\begin{tabular}{|c|c|c|c|c|c|c|}
\hline & Before & After & \multirow{2}{*}{$p$} & Before & After & \multirow{2}{*}{$p$} \\
\hline & \multicolumn{2}{|c|}{$\begin{array}{c}\text { SW } \\
\text { (MET/week) }\end{array}$} & & \multicolumn{2}{|c|}{$\begin{array}{c}\text { AW } \\
\text { (MET/week) }\end{array}$} & \\
\hline Walking & $587 \pm 80$ & $664 \pm 124$ & .57 & $552 \pm 113$ & $472 \pm 88$ & .56 \\
\hline $\begin{array}{l}\text { Moderate } \\
\text { Activity }\end{array}$ & $203 \pm 95$ & $293 \pm 82$ & .42 & $328 \pm 101$ & $588 \pm 213$ & .24 \\
\hline $\begin{array}{l}\text { Vigorous } \\
\text { Activity }\end{array}$ & $487 \pm 210$ & $747 \pm 220$ & .29 & $160 \pm 84$ & $456 \pm 282$ & .38 \\
\hline $\begin{array}{l}\text { Total } \\
\text { Activities }\end{array}$ & $1278 \pm 310$ & $1706 \pm 378$ & .29 & $1040 \pm 231$ & $1352 \pm 395$ & .26 \\
\hline
\end{tabular}

The values are expressed as the mean + SEM. $\mathrm{SW}=$ storage workers; $\mathrm{AW}=$ computer-using administrative workers; and $\mathrm{MET}=$ metabolic equivalent.

\section{Musculoskeletal complaints}

We observed that the SBP decreased the complaints of paresthesias and numbness during the last 7 days in the upper body (by $73 \%$, from 11 to $3, p=.02$ ) and total body (by $55 \%$, from 20 to $9, p=.04$ ) in the SW group (Table 3); for the AW group, participation in the SBP decreased complaints of paresthesias 
and numbness over the last 12 months in the upper body (by $46 \%, 43$ to 23 from $p=.02$ ) (Table 4 ). The lower limbs were not affected by the SBP in either group. Furthermore, implementing the SBP did not alter the number of workers who were prevented from performing their regular activities (work, housework and leisure) or the number of workers who sought health professionals because of symptoms within the last 12 months (Tables 3 and 4).

Table 3. Number of musculoskeletal symptoms reported by the SW before and after the 6-month stretch break program.

\begin{tabular}{|c|c|c|c|}
\hline Upper Limbs & Before SBP & After SBP & $p$ \\
\hline Musculoskeletal symptoms $12 \mathrm{~m}$ & 19 & 15 & .13 \\
\hline Prevented from performing activities & 0 & 1 & .33 \\
\hline Sought care from a health professional & 4 & 0 & .08 \\
\hline Musculoskeletal symptoms $7 \mathrm{~d}$ & 11 & $3 *$ & .02 \\
\hline Lower Limbs & Before SBP & After SBP & \\
\hline Musculoskeletal symptoms $12 \mathrm{~m}$ & 11 & 10 & .90 \\
\hline Prevented from performing activities & 4 & 2 & .75 \\
\hline Sought care from a health professional & 3 & 2 & .83 \\
\hline Musculoskeletal symptoms $7 \mathrm{~d}$ & 9 & 6 & .33 \\
\hline Total & Before SBP & After SBP & \\
\hline Musculoskeletal symptoms $12 \mathrm{~m}$ & 30 & 25 & .33 \\
\hline Prevented from performing activities & 4 & 3 & .93 \\
\hline Sought care from a health professional & 7 & 2 & .25 \\
\hline Musculoskeletal symptoms $7 \mathrm{~d}$ & 20 & $9 *$ & .04 \\
\hline
\end{tabular}

The values are expressed as the mean + SEM. $12 \mathrm{~m}=$ the last 12 months and $7 \mathrm{~d}=$ the last seven days. ${ }^{*} p<.05$ for comparisons of the measurements at 0 and 6 months.

Table 4. Number of musculoskeletal symptoms reported by the AW before and after the 6-month stretch break program.

\begin{tabular}{|c|c|c|c|}
\hline Upper Limbs & Before SBP & After SBP & $p$ \\
\hline Musculoskeletal symptoms 12 m & 43 & $23 *$ & .02 \\
\hline Prevented from performing activities & 4 & 8 & .18 \\
\hline Sought care from a health professional & 5 & 10 & .09 \\
\hline Musculoskeletal symptoms $7 \mathrm{~d}$ & 5 & 3 & .34 \\
\hline Lower Limbs & Before SBP & After SBP & \\
\hline Musculoskeletal symptoms $12 \mathrm{~m}$ & 7 & 7 & .77 \\
\hline Prevented from performing activities & 1 & 0 & .34 \\
\hline Sought care from a health professiona & 1 & 2 & .59 \\
\hline Musculoskeletal symptoms $7 \mathrm{~d}$ & 1 & 0 & .34 \\
\hline Total & Before SBP & After SBP & \\
\hline Musculoskeletal symptoms $12 \mathrm{~m}$ & 50 & 30 & .10 \\
\hline Prevented from performing activities & 5 & 6 & .34 \\
\hline Sought care from a health professional & 6 & 12 & .35 \\
\hline Musculoskeletal symptoms $7 \mathrm{~d}$ & 6 & 13 & .34 \\
\hline
\end{tabular}

The values are expressed as the mean + SEM. $12 \mathrm{~m}=$ the last 12 months and $7 \mathrm{~d}=$ the last seven days. ${ }^{*} p<.05$ for comparisons of the measurements at 0 and 6 months.

\section{Flexibility}

The six-month SBP did not improve the flexibility of the hamstring muscles, hips and lumbosacral regions, as evaluated by the sit-and-reach test, in either the SW (from $24.8 \pm 2.9 \mathrm{~cm}$ to $26.1 \pm 3.0 \mathrm{~cm}, p=.017$ ) or the AW group (from $16.4 \pm 2.9$ $\mathrm{cm}$ to $15.9 \pm 2.7 \mathrm{~cm}, p=.65$; Table 5).

Cervical and shoulder flexibility did not differ between the right and left sides in the AW and SW groups before or after the SBP. There were also no differences in the trunk flexibility of the right and left sides of the AW group before or after the SBP. However, in the SW group, the trunk flexibility was lower on the left side than the right side before the SBP $(p=$ .007 ) but not after SBP (Table 5). After the 6-month SBP, we observed improvements in right and left cervical flexibility (by approximately $8 \%, p=.02$ ), right and left trunk flexibility (by approximately $15-20 \%, p=.0001$ ) and left shoulder flexibility (by $4 \%, p=.03$ ) in the SW group and in the right and left cervical flexibility (by $15 \%, p=.03$ and by $11 \%, p$ $=.04$, respectively) and the right and left shoulder flexibility (by approximately $10 \%, p=.005$ and $p=.003$, respectively) in the AW group (Table 5). 
Table 5. Flexibility before and after the 6-month stretch break program.

\begin{tabular}{|c|c|c|c|c|c|c|}
\hline & Before & After & & Before & After & \\
\hline & & & $p$ & & & $p$ \\
\hline Volunteers & & & & & & \\
\hline SRT (cm) & $25 \pm 3$ & $26 \pm 3$ & .17 & $16.4 \pm 3$ & $15.9 \pm 3$ & .65 \\
\hline R Cervical (degrees) & $50 \pm 3$ & $55 \pm 2 *$ & .03 & $45 \pm 3$ & $51 \pm 4 *$ & .03 \\
\hline L Cervical (degrees) & $48 \pm 2$ & $52 \pm 2 *$ & .02 & $44 \pm 2$ & $49 \pm 2 *$ & .05 \\
\hline R Shoulder (degrees) & $152 \pm 3$ & $149 \pm 3$ & .49 & $149 \pm 4$ & $166 \pm 3^{*}$ & .005 \\
\hline L Shoulder (degrees) & $149 \pm 3$ & $156 \pm 2 *$ & .03 & $149 \pm 3$ & $165 \pm 3^{*}$ & .003 \\
\hline R Trunk (degrees) & $43 \pm 2$ & $50 \pm 2 *$ & .01 & $41 \pm 2$ & $46 \pm 1$ & .12 \\
\hline L Trunk (degrees) & $40 \pm 1 \#$ & $49 \pm 2 *$ & .01 & $42 \pm 2$ & $45 \pm 2$ & .12 \\
\hline
\end{tabular}

The values are expressed as the mean $+\mathrm{SEM} . \mathrm{SW}=$ storage workers and $\mathrm{AW}=$ computer-using administrative workers. $\mathrm{SRT}=$ Sit-and-Reach Test. $\mathrm{R}=$ right; $\mathrm{L}=$ left. * $p<.05$ for comparisons of measurements at 0 and 6 months. $\# p<.05$ for comparisons between the $\mathrm{R}$ trunk and the $\mathrm{L}$ trunk.

\section{Grip strength}

Before implementing the SBP, the grip strength of the SW group was higher than the AW group on both the DS (from $39.9 \pm 1.4$ to $33.7 \pm 1.8 \mathrm{~kg}, p=.0163$ ) and the NDS (from $37.3 \pm 1.1$ to $29.8 \pm 1.9 \mathrm{~kg}, p=.0043$ ) (Table 6). The SBP did not alter the grip strength in the SW group and increased the grip strength on the DS and the NDS in the AW group. In the AW group, grip strength was greater on the DS only before the SBP. In the SW group, grip strength was greater on the DS compared with the NDS both before and after the SBP (Table 6).

Table 6. Grip strength before and after the 6-month stretch break program.

\begin{tabular}{|c|c|c|c|c|c|c|}
\hline & Before & After & \multirow{2}{*}{$p$} & Before & After & \multirow{2}{*}{$p$} \\
\hline & \multicolumn{2}{|c|}{ SW } & & \multicolumn{2}{|c|}{ AW } & \\
\hline Volunteers & & & \multicolumn{3}{|c|}{10} & \\
\hline Dominant (Kg) & $40 \pm 1$ & $40 \pm 1$ & .65 & $34 \pm 2$ & $40 \pm 3 *$ & .02 \\
\hline Non-dominant $(\mathrm{Kg})$ & $37 \pm 1 \#$ & $37 \pm 1 \#$ & .81 & $30 \pm 2 \#$ & $36 \pm 2 *$ & .001 \\
\hline$p$ & .01 & .03 & & .001 & .11 & \\
\hline
\end{tabular}

The values are expressed as the mean + SEM. $\mathrm{SW}=$ storage workers and AW = computer-using administrative workers. Kg, kilograms. $\# p<.05$ for comparisons between the dominant and non-dominant sides. ${ }^{*} p<.05$ for comparisons between 0 and 6 months.

\section{Discussion}

Our findings demonstrated that a 6-month strength break program reduced musculoskeletal discomfort in different body segments and improved the flexibility and grip strength of storage and administrative workers. Prior studies have shown that musculoskeletal symptoms may be immediately reduced by taking stretch breaks and by increasing the frequency of such breaks (Hagberg \& Sundelin, 1986; Sundelin \& Hagberg, 1989). Van Den Heuvel et al. (2003) observed a decrease in musculoskeletal symptoms and higher productivity among the workers in pause-and-stretch break intervention groups compared with a control group. Silverstein, Armstrong, Longmate \& Woody (1988) reported that assembly line workers who participated in a stretch break program reported better recovery from discomfort despite the lack of significant reductions in symptoms upon assessment. Recently, a systematic review concluded that there are no evidences regarding the effectiveness of work disability prevention such as neck pain and upper extremity disorders. However, the researchers suggested that a return-to-work coordination program is more effective than clinic-based work hardening and that strength breaks and workplace interventions benefits workers' recovery (Varatharajan et al., 2014).

Previous studies have suggested that improving muscle strength and flexibility avoids CTD and musculoskeletal symptoms (Johnston et al., 2014; Moreira-Silva, Santos, Abreu \& Mota, 2014; Pedersen, Andersen, Zebis, Sjøgaard, \& Andersen, 2013). The CTD reductions occurs during training phase with supervision and appears to be maintained a half year later, and can avoid symptoms on a low level but does not result in further pain reduction (Perdersen et al., 2013). All of the participants in the AW group and most of the participants in the SW group exhibited below-average flexibility (from 30 to 33 $\mathrm{cm}$ ) in their hamstring muscles, hips and lumbosacral regions. Improvements in lateral flexibility and muscle tension were observed among the metallurgical company workers, along with a decrease in the number of pain complaints and the number of painful segments, making a significant number of the participants asymptomatic. Fenety et al. (2002) and Feuerstein et al. (2004) demonstrated that implementing exercise programs led to significant reductions in musculoskeletal discomfort, postural immobility and functional limitations. The SBP increased flexibility in the cervical, trunk, and shoulder (left side) regions 
in the SW group and the shoulder (right and left sides) and cervical regions in the $\mathrm{AW}$ group. The improved flexibility might have decreased the workers' complaints about paresthesias and numbness in their upper and total body regions.

However, the SBP did not alter the flexibility of the hamstring muscles, hips or lumbosacral regions in either group. The SBP was focused on the neck, shoulders, back, and upper extremities (hands and wrist) and not specifically on the hamstring muscles, hips or lumbosacral regions; this design may explain why the program had no effect on the flexibility of these regions. Lowe and Dick (2015) suggested that the effect of workplace exercise is minimal and effective as tertiary prevention and therapeutic relief of neck/shoulder symptoms. Moreover, previous studies have demonstrated that specific exercise programs improves strength and resistance levels of the trunk and lumbar extensors (Andersen et al., 2012; Carvalho Mesquita, Ribeiro, \& Moreira, 2012; Koumantakis, Watson, \& Oldham, 2005), and these improvements appear after 6 to 8 months (Cohen, Goel, Frank, \& Gibson, 1994). A 10-week yoga intervention delivered improves flexibility, state anxiety and musculoskeletal fitness in office positions workers (Cheema et al., 2013). Supervised qigong, Iyengar yoga, or combined programs including strengthening, and flexibility appears also to be effective for the management of neck symptoms (Southerst et al., 2014).

Postures or movements that engage antagonist muscle groups promote greater or lesser elongation, resulting in a mechanical disadvantage and weakness. In addition, certain positions increase the pressure or the extension of the nerves in the extremities, which results in chronic nerve compression, reducing blood flow, causing fibrosis, and impairing normal movement of the region or nerve (Higgs \& Mackinnon, 1995). The occupational activities of the SW group involve manipulating storage boxes, relying more heavily on the right side of the shoulder and the trunk because all of the participants were right-hand. Thus, the SW group exhibited greater right trunk flexibility than left trunk flexibility before the SBP, and the SBP increased the trunk flexibility of both sides, creating balance between the two sides. However, the SBP only increased the flexibility of the non-dominant left shoulder. We suggest that right shoulder was more used to manipulating boxes than the right trunk because of the varying surface levels, hampering the effect of SBP.

Strength training relying on principles of progressive overload implemented in workers also reduces neck and shoulder pain (Zebis et al., 2011). Sundstrup et al. (Sundstrup et al., 2013, 2014) demonstrated that workplace initiatives reduce musculoskeletal pain among employees who perform repetitive and forceful work with their arms, shoulders and hands. Maintaining or increasing grip strength may be effective for preventing wrist injuries in computer users. Matias et al. (1998) reported that the incidence of wrist injuries is 8 to $38 \%$ and the probability of injury is $40 \%$ among computer workers. Rasotto et al. (2015) reported an improvement on upper limb pain and neck disability with concomitant increases in grip strength. The grip strength on the DS and the NDS was higher in the SW group compared with the AW group. Implementing the SBP increased the AW group's grip strength both on the DS and the NDS, but it had no effect on the SW group. In other studies, increasing the frequency of pause breaks improved the workers' accuracy and/or speed during computer use (Balci \& Aghazadeh, 2003; Kopardekar \& Mital, 1994). Restrictions on workers' pause breaks during computer use have been identified as risk factors for musculoskeletal symptoms and injuries (Bergqvist, Wolgast, Nilsson, \& Voss, 1995a, 1995b).

Our study presented the subjective evaluations of workers who participated in a 6-month SBP and the physiological effects of the program. Both the subjective evaluations and the physiological analyses revealed improvements in flexibility and a decrease in the number of reports of discomfort and other problems. Most of the studies on this subject have controlled for and investigated exercises using questionnaires and subjective evaluations that were compared to data regarding sick leave and/or medical treatments.

\section{Conclusion}

The reduction in musculoskeletal symptoms and the improvements in flexibility and grip strength during the 6-month intervention period demonstrate the importance of implementing and maintaining health promotion and physical activity programs in the work environment. We conclude that the SBP improved grip strength in the AW group and improved the flexibility of the body regions that are prone to work-related injuries in both groups. Ultimately, the SBP reduced the number of musculoskeletal complaints.

\section{References}

Andersen, C.H., Andersen, L.L., Gram, B., Pedersen, M.T., Mortensen, O.S., Zebis, M.K., \& Sjøgaard, G. (2012). Influence of frequency and duration of strength training for effective management of neck and shoulder pain: a randomized controlled trial. British Journal of Sports Medicine, 46, 1004-1010.

Balci, R., \& Aghazadeh, F. (2003). The effect of work-rest schedules and type of task on the discomfort and performance of VDT users. Ergonomics, 46, 455-465.

Balci, R., \& Aghazadeh, F. (2004). Effects of exercise breaks on performance, muscular load and perceived discomfort in data entry and cognitive tasks. Computers \& Industrial Engineering, 46, 399-411.

Bergqvist, U., Wolgast, E., Nilsson, B., \& Voss, M. (1995a). The influence of VDT work on musculoskeletal disorders. Ergonomics, 38, 754-762.

Bergqvist, U., Wolgast, E., Nilsson, B., \& Voss, M. (1995b). Musculoskeletal disorders among visual display terminal workers: individual, ergonomic, and work organizational factors. Ergonomics, 38, 763-776.

Bernaards, C.M., Ariens, G.A., \& Hildebrandt, V.H. (2006). The (cost-) effectiveness of a lifestyle physical activity intervention in addition to a work style intervention on the recovery from neck and upper limb symptoms in computer workers. BMC Musculoskeletal Disorders, 7, 80.

Bongers, P.M., Ijmker, S., van den Heuvel, S., \& Blatter, B.M. (2006). Epidemiology of work related neck and upper limb problems: 
psychosocial and personal risk factors (part I) and effective interventions from a bio behavioural perspective (part II). Journal of Occupational Rehabilitation, 16, 279-302.

Brewer, S., Van Eerd, D., Amick, B. C., Irvin, E., Daum, K.M., Gerr, F., \& Rempel, D. (2006). Workplace interventions to prevent musculoskeletal and visual symptoms and disorders among computer users: a systematic review. Journal of Occupational Rehabilitation, 16, 325-358.

Canadian Ministry of State (1987). Canadian Standardized Test of Fitness (CSTI) Operations Manual (3rd ed.). Ottawa, DC: Government of Canada, Fitness and Amateur Sport.

Carvalho Mesquita, C., Ribeiro, J.C., \& Moreira, P. (2012). Effect of a specific exercise program on the strength and resistance levels of lumbar muscles in warehouse workers. International Journal of Occupational Medicine and Environmental Health, $25,80-88$.

Cheema, B.S., Houridis, A., Busch, L., Raschke-Cheema, V., Melville, G.W., Marshall, P.W., ... Colagiuri, B. (2013). Effect of an office worksite-based yoga program on heart rate variability: outcomes of a randomized controlled trial. BMC Complementary and Alternative Medicine, 13, 82-92.

Cohen, J.E., Goel, V., Frank, J. W., \& Gibson, E.S. (1994). Predicting risk of back injuries, work absenteeism, and chronic disability. The shortcomings of preplacement screening. Journal of Occupational Medicine, 36, 1093-1099.

Dick, F.D., Graveling, R.A., Munro, W., \& Walker-Bone, K. (2011). Workplace management of upper limb disorders: a systematic review. Occupational Medicine, 61, 19-25.

Fenety, A., \& Walker, J.M. (2002). Short-term effects of workstation exercises on musculoskeletal discomfort and postural changes in seated video display unit workers. Physical Therapy, 82, 578-589.

Feuerstein, M., Nicholas, R.A., Huang, G.D., Dimberg, L., Ali, D., \& Rogers, H. (2004). Job stress management and ergonomic intervention for work-related upper extremity symptoms. Applied Ergonomics, 35, 565-574.

Hagberg, M., \& Sundelin, G. (1986). Discomfort and load on the upper trapezius muscle when operating a wordprocessor. Ergonomics, 29(12), 1637-1645.

Heinrich, J., \& Blatter, B.M. (2005). RSI symptoms in the Dutch labour force. Trends, risk factors and explanations. Tijdschrift voor gezondheidswetenschappen, 83, 16-24.

Henning, R.A., Jacques, P., Kissel, G.V., Sullivan, A.B., \& AlterasWebb, S.M. (1997). Frequent short rest breaks from computer work: effects on productivity and well-being at two field sites. Ergonomics, 40(1), 78-91.

Higgs, P.E., \& Mackinnon, S.E. (1995). Repetitive motion injuries. Annual Review of Medicine, 46, 1-16.

Johnston, V., O’Leary, S., Comans, T., Straker, L., Melloh, M., Khan, A., \& Sjøgaard, G. (2014). A workplace exercise versus health promotion intervention to prevent and reduce the economic and personal burden of non-specific neck pain in office personnel: protocol of a cluster-randomised controlled trial. Journal of Physiotherapy, 60, 233.

Karwowski, W., Eberts, R., Salvendy, G., \& Noland, S. (1994). The effects of computer interface design on human postural dynamics. Ergonomics, 37, 703-724.
Kopardekar, P., \& Mital, A. (1994). The effect of different work-rest schedules on fatigue and performance of a simulated directory assistance operator's task. Ergonomics, 37, 1697-1707.

Koumantakis, G.A., Watson, P.J., \& Oldham, J.A. (2005). Supplementation of general endurance exercise with stabilisation training versus general exercise only. Physiological and functional outcomes of a randomised controlled trial of patients with recurrent low back pain. Clinical Biomechanics, 20, 474-482.

Kraker, H.D., \& Blatter, B.M. (2005). Prevalence of RSI-complaints and the occurrence of risk factors in 15 European countries. Tijdschr Gezondheidsw, 83, 8-15.

Kuorinka, I., Jonsson, B., Kilbom, A., Vinterberg, H., Biering-Sørensen, F., Andersson, G., \& Jørgensen K. (1987). Standardised Nordic questionnaires for the analysis of musculoskeletal symptoms. Applied Ergonomics, 18, 233-237.

Leighton, J.R. (1987). Manual of instruction for Leighton Flexometer. New York: AS Barnes \& Co.

Lowe, B.D., \& Dick, R.B. (2015). Workplace exercise for control of occupational neck/shoulder disorders: a review of prospective studies. Environmental Health Insights, 26,75-95.

Matias, A.C., Salvendy, G., \& Kuczek, T. (1998). Predictive models of carpal tunnel syndrome causation among VDT operators. Ergonomics, 41, 213-226.

McLean, L., Tingley, M., Scott, R.N., \& Rickards, J. (2001). Computer terminal work and the benefit of microbreaks. Applied Ergonomics, 32(3), 225-237.

Moreira-Silva, I., Santos, R., Abreu, S. \& Mota, J. (2014). The effect of a physical activity program on decreasing physical disability indicated by musculoskeletal pain and related symptoms among workers: a pilot study. International Journal of Occupational Safety Ergonomics, 20, 55-64.

Pedersen, M.T., Andersen, C.H., Zebis, M.K., Sjøgaard, G., \& Andersen, L.L. (2013). Implementation of specific strength training among industrial laboratory technicians: long-term effects on back, neck and upper extremity pain. BMC Musculoskeletal Disorders, 14, 287-298.

Peters, M.J., van Nes, S.I., Vanhoutte, E.K., Bakkers, M., van Doorn, P.A., Merkies, I.S., \& Faber, C.G. (2011). Revised normative values for grip strength with the Jamar dynamometer. Journal of the Peripheral Nervous Systems, 16, 47-50.

Rasotto, C., Bergamin, M., Sieverdes, J.C., Gobbo, S., Alberton, C.L., Neunhaeuserer, D., ... Ermolao A. (2015). A tailored workplace exercise program for women at risk for neck and upper limb musculoskeletal disorders: a randomized controlled trial. Journal of Occupational Environmental Medicine, 57,178-183.

Silverstein, B.A., Armstrong, T.J., Longmate, A., \& Woody, D. (1988). Can inplant exercise control musculoskeletal symptoms? Jounal of Occupational Medicine, 30, 922-927.

Southerst, D., Nordin, M.C., Côté, P., Shearer, H.M., Varatharajan, S., Yu, H., ... Taylor-Vaisey, A.L. (2014). Is exercise effective for the management of neck pain and associated disorders or whiplash-associated disorders? A systematic review by the Ontario Protocol for Traffic Injury Management (OPTIMa) Collaboration. The Spine Journal, S1529-9430, 00210-1.

Sundelin, G., \& Hagberg, M. (1989). The effects of different pause types on neck and shoulder EMG activity during VDU work. Ergonomics, 32, 527-537. 
Sundstrup, E., Jakobsen, M.D., Andersen, C.H., Jay, K., Persson, R., Aagaard, P., \& Andersen, L.L. (2013). Participatory ergonomic intervention versus strength training on chronic pain and work disability in slaughterhouse workers: study protocol for a single-blind, randomized controlled trial. BMC Musculoskeletal Disorders, 14, 67.

Sundstrup, E., Jakobsen, M.D., Andersen, C.H., Jay, K., Persson, R., Aagaard, P., \& Andersen, L.L. (2014). Effect of two contrasting interventions on upper limb chronic pain and disability: a randomized controlled trial. Pain Physician, 17,145-54.

Trujillo, L., \& Zeng, X. (2006). Data entry workers perceptions and satisfaction response to the "stop and stretch" software program. Work, 27, 111-121.

Van Den Heuvel, S.G., Looze de, M.P., Hildebrandt, V.H., \& The, K.H. (2003). Effects of software programs stimulating regular breaks and exercises on work-related neck and upper-limb disorders. Scandinavian Journal of Work, Environment \& Health, 29, 106-116.

Van den Heuvel, S.G., Van der Beek, A.J., Blatter, B.M., \& Bongers, P.M. (2006). Do work-related physical factors predict neck and upper limb symptoms in office workers? International Archives of Occupational and Environmental Health, 79, 585-592.

Varatharajan S., Côté P., Shearer, H.M., Loisel, P., Wong, J.J., Southerst, D., ... Taylor-Vaisey, A. (2014) Are work disability prevention interventions effective for the management of neck pain or upper extremity disorders? A systematic review by the Ontario Protocol for Traffic Injury Management (OPTIMa) collaboration. Journal of Occupational Rehabilitation, 24, 692-708.

Wolin, K.Y., Heil, D.P., Askew, S., Matthews, C.E., \& Bennett, G.G. (2008). Validation of the International Physical Activity Questionnaire-Short among Blacks. Journal of Physical Activity \& Health, 5, 746-760.

Zebis, M.K., Andersen, L.L., Pedersen, M.T., Mortensen, P., Andersen, C.H., Pedersen M.M., ... Sjøgaard, G. (2011). Implementation of neck/ shoulder exercises for pain relief among industrial workers: a randomized controlled trial. BMC Musculoskeletal Disorders, 12, 205-214.

\section{Authors' note}

Patrícia Fátima de Oliveira Martins, Evelin Alvares Aranda Zicolau, and Maria Fernanda Cury-Boaventura are affiliated with the Instituto de Ciências da Atividade Física e Esporte, Programa de Pós Graduação em Ciências do Movimento Humano, Universidade Cruzeiro do Sul, São Paulo, Brazil.

\section{Corresponding author}

Maria Fernanda Cury Boaventura, Institute of Physical Activity and Sports Sciences, Post-Graduate Program in Human Movement Sciences, Cruzeiro do Sul University, Rua Galvão Bueno, 868, CEP 01506-000, São Paulo, SP, Brazil.

Phone: 55 - 11 - 33853103. Fax: $55-11$ - 3385-3003.

E-mail: maria.boaventura@cruzeirodosul.edu.br

\section{Acknowledgements}

The authors are grateful to Luciana Carvalho, physical education teacher who introduced and performed the exercises, corrected the participants and coordinated the educational information notices and satisfaction surveys. This research was supported by the São Paulo Research Foundation (FAPESP).

Manuscript received on March 4, 2014

Manuscript accepted on July 7, 2015

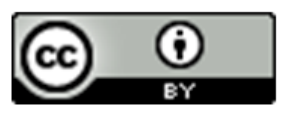

Motriz. The Journal of Physical Education. UNESP. Rio Claro, SP, Brazil - eISSN: 1980-6574 - under a license Creative Commons - Version 3.0 
Appendix 1. Monthly planning of SBP in AW and SW: joints, movements and mainly muscle groups.

\begin{tabular}{|c|c|c|}
\hline \multicolumn{3}{|c|}{ First and Third Week } \\
\hline Monday & Wednesday & Friday (\#) \\
\hline Upper Limbs & Lower Limbs & Upper and Lower Limbs \\
\hline $\begin{array}{l}\text { Shoulder } \\
\text { flexion, extension, adduction and abduction } \\
\text { Deltoid } \mathrm{m} \text {. } \\
\text { Biceps brachii } \mathrm{m} \text {. } \\
\text { Pectoralis major and minor } \mathrm{m} . \\
\text { Supraspinatus } \mathrm{m} \text {. } \\
\text { Trapezius } \mathrm{m} . \\
\text { Neck } \\
\text { flexion, extension and rotation and lateral } \\
\text { flexion } \\
\text { Sternocleidomastoid } \mathrm{m} \text {. } \\
\text { long neck m. } \\
\text { semispinalis capitis } \mathrm{m} \text {. } \\
\text { splenius capitis } \mathrm{m} . \\
\text { Trunk } \\
\text { flexion, extension and rotation and lateral } \\
\text { flexion } \\
\text { rectos abdominis } \mathrm{m} \text {. } \\
\text { internal and external oblique } \mathrm{m} . \\
\text { semispinalis } \mathrm{m} \text {. } \\
\text { Rotators m. } \\
\text { Iliocostal m. }\end{array}$ & 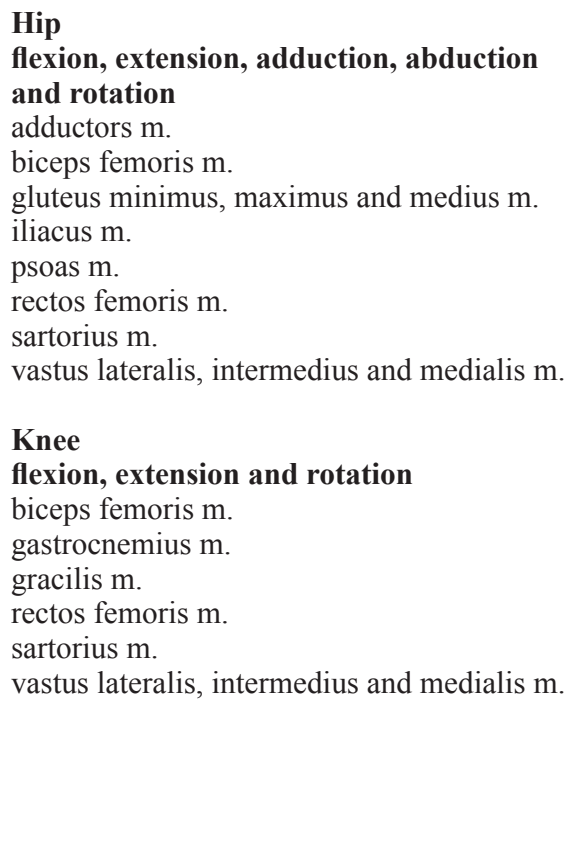 & 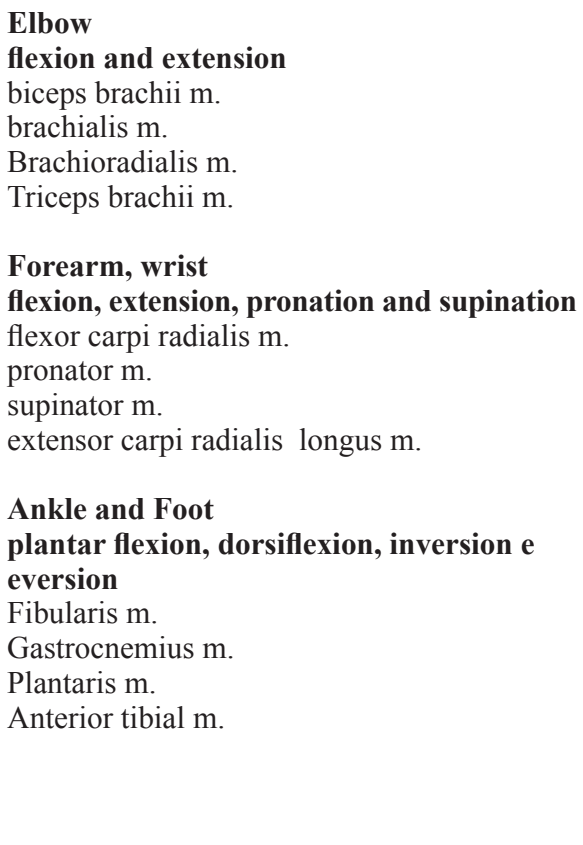 \\
\hline $\begin{array}{l}\text { Hands and fingers } \\
\text { abduction, adduction, flexion, extension } \\
\text { flexor carpi radialis } \mathrm{m} \text {. } \\
\text { flexor digitorum profundus and superficialis } \\
\mathrm{m} \text {. } \\
\text { extensor digitorum } \mathrm{m} \text {. } \\
\text { abductor pollicis longus } \mathrm{m} \text {. } \\
\text { adductor pollicis } \mathrm{m} \text {. }\end{array}$ & & \\
\hline
\end{tabular}

\begin{tabular}{|c|c|c|}
\hline \multicolumn{3}{|c|}{ Second and Fourth Week } \\
\hline Monday & Wednesday & Friday (\#) \\
\hline Upper Limbs & Lower Limbs & Upper and Lower Limbs \\
\hline $\begin{array}{l}\text { Elbow } \\
\text { flexion and extension } \\
\text { biceps brachii m. } \\
\text { brachialis } \mathrm{m} \text {. } \\
\text { Brachioradialis } \mathrm{m} . \\
\text { Triceps brachii } \mathrm{m} . \\
\text { Forearm and wrist } \\
\text { flexion, extension, pronation and supination } \\
\text { flexor carpi radialis m. } \\
\text { pronator } \mathrm{m} \text {. } \\
\text { supinator m. } \\
\text { extensor carpi radialis longus m. } \\
\text { Hands and fingers } \\
\text { (\#\#) } \\
\text { abduction, adduction, flexion, extension } \\
\text { flexor carpi radialis m. } \\
\text { flexor digitorum profundus and superficialis m. } \\
\text { extensor digitorum m. } \\
\text { abductor pollicis longus m. } \\
\text { adductor pollicis m. }\end{array}$ & $\begin{array}{l}\text { Hip } \\
\text { flexion, extension, adduction, abduction } \\
\text { and rotation } \\
\text { adductors } \mathrm{m} \text {. } \\
\text { biceps femoris } \mathrm{m} \text {. } \\
\text { gluteus minimus, maximus e medius } \mathrm{m} . \\
\text { iliacus } \mathrm{m} . \\
\text { psoas } \mathrm{m} . \\
\text { rectos femoris } \mathrm{m} \text {. } \\
\text { sartorius } \mathrm{m} . \\
\text { vastus lateralis, intermedius and medialis m. } \\
\text { Ankle and Foot } \\
\text { plantar flexion, dorsiflexion, inversion and } \\
\text { eversion } \\
\text { Fibularis m. } \\
\text { Gastrocnemius } \mathrm{m} \text {. } \\
\text { Plantaris } \mathrm{m} . \\
\text { Anterior tibial } \mathrm{m} .\end{array}$ & $\begin{array}{l}\text { Trunk } \\
\text { flexion, extension and rotation and lateral } \\
\text { flexion } \\
\text { rectos abdominais } \mathrm{m} \text {. } \\
\text { internal and external oblique } \mathrm{m} . \\
\text { semispinalis } \mathrm{m} \text {. } \\
\text { Rotators } \mathrm{m} . \\
\text { Iliocostal } \mathrm{m} \text {. } \\
\text { Hip } \\
\text { flexion, extension, aduction, abduction and } \\
\text { rotation } \\
\text { adductors } \mathrm{m} \text {. } \\
\text { biceps femoris } \mathrm{m} \text {. } \\
\text { gluteus minimus, maximus e medius } \\
\text { iliacus } \mathrm{m} \text {. } \\
\text { psoas m. } \\
\text { rectos femoris m. } \\
\text { sartorius } \mathrm{m} \text {. } \\
\text { vastus lateralis, intermedius and medialis } \mathrm{m} \text {. }\end{array}$ \\
\hline
\end{tabular}

\# Exclusive for SW; \#\# Exclusive for AW 